\title{
Evolving concepts on the role of dyslipidemia, bioenergetics, and inflammation in the pathogenesis and treatment of diabetic peripheral neuropathy
}

\author{
Amro M. Stino $^{1,2}$ | Amy E. Rumora ${ }^{1}$ | Bhumsoo Kim ${ }^{1}$ (c) | Eva L. Feldman ${ }^{1,2}$
}

${ }^{1}$ Department of Neurology, University of Michigan School of Medicine, Ann Arbor, Michigan

${ }^{2}$ Division of Neuromuscular Medicine, Ann Arbor, Michigan

\section{Correspondence}

Amro M. Stino, Department of Neurology, University of Michigan School of Medicine, Ann Arbor, MI 48109.

Email: amstino@med.umich.edu

\section{Funding information}

NeuroNEXT Network \& National Institute of Neurological Disorders and Stroke; NIDDK, Grant/Award Number: K99DK119366; NIH, Grant/Award Numbers: R01D107956, R21NS102924, R24DK082841; The A. Alfred Taubman Biomedical Research Institute; The Neuronetwork for Emerging Therapies at Michigan Medicine

\begin{abstract}
Diabetic peripheral neuropathy (DPN) is one of the most widespread and disabling neurological conditions, accounting for half of all neuropathy cases worldwide. Despite its high prevalence, no approved disease modifying therapies exist. There is now a growing body of evidence that DPN secondary to type 1 diabetes mellitus (T1DM) and type 2 diabetes mellitus (T2DM) represents different disease processes, with T2DM DPN best understood within the context of metabolic syndrome rather than hyperglycemia. In this review, we highlight currently understood mechanisms of DPN, along with their corresponding potential therapeutic targets. We frame this discussion within a practical overview of how the field evolved from initial human observations to murine pathomechanistic and therapeutic models into ongoing and human clinical trials, with particular emphasis on T2DM DPN and metabolic syndrome.

KEYWORDS

diabetic peripheral neuropathy, metabolic syndrome, modern concepts, novel therapy, pathophysiology
\end{abstract}

\section{1 | INTRODUCTION}

Diabetic peripheral neuropathy (DPN) is a length-dependent sensory predominant axonal neuropathy that often first manifests with dysesthesias, pain, numbness, or imbalance. DPN has a prevalence ranging from $10 \%$ to 50\% for both type 1 diabetes (T1DM) and type 2 diabetes (T2DM). The DPN annual cost, including complications, exceeds $\$ 10$ billion in the United States alone. ${ }^{1}$ DPN leads to reduced quality of life due to increased pain, falls, lower limb ulcers, and amputations. While glycemic control has been shown to be effective in DPN associated with T1DM, it carries only a modest effect in DPN associated with T2DM., ${ }^{2,3}$ Furthermore, while neuropathy associated with T1DM and T2DM has classically been categorized together, we now know that the two are largely different disease processes. ${ }^{4,5}$ Despite recent clinical testing of contemporary drugs (Table 1) and decades of research on a massive global health burden, no approved disease-modifying therapies exist. Previous drug trials focused on antioxidants $^{12-18}$; lipid lowering fibrates ${ }^{16,19}$; aldose reductase inhibitors ${ }^{20-23}$; neurotrophic factors ${ }^{24-26}$; GABA analogues ${ }^{27}$; cellular metabolism agonists $^{28-31}$; and vasodilators ${ }^{13,32}$ and have had limited efficacy in treating DPN associated with T1DM and T2DM. ${ }^{33,34}$ Nevertheless, with our increased understanding of DPN pathogenesis, there is general optimism that new therapies for DPN are on the horizon. In this review, we focus on our current understanding of DPN pathogenesis and potential therapeutic targets, with a particular focus on DPN in the setting of T2DM and metabolic syndrome (MetS). We highlight how initial clinical observations in patients led to the development of murine models of T2DM and prediabetes, which guided our understanding of pathomechanisms and potential therapies. These studies inform ongoing and future clinical trials and our approach to identifying disease modifying therapies.

\section{2 | CRYPTOGENIC SENSORY PERIPHERAL NEUROPATHY AND METABOLIC SYNDROME}

Clinicians caring for patients with cryptogenic sensory peripheral neuropathy (CSPN) in the 1990 s observed that many patients without 
TABLE 1 Drug trials on peripheral neuropathy associated with T1DM and T2DM from 2010 to 2020

\begin{tabular}{|c|c|c|c|c|c|}
\hline Drug & $\begin{array}{l}\text { Disease or } \\
\text { pain modifying }\end{array}$ & Mechanism of action & $\begin{array}{l}\text { Diabetes } \\
\text { type }\end{array}$ & $\begin{array}{l}\text { Clinical trial outcome for } \\
\text { neuropathy }\end{array}$ & Reference \\
\hline $\begin{array}{l}\text { OnabotulintoxinA } \\
\text { (BoNT/A) }\end{array}$ & Pain & $\begin{array}{l}\text { Inhibits neurogenic inflammation } \\
\text { from peripheral nociceptive nerve } \\
\text { terminals }\end{array}$ & T2DM & $\begin{array}{l}\text { Improved tactile and mechanical } \\
\text { pain perception in painful DPN }\end{array}$ & 6 \\
\hline Botulin toxin (BTX-A) & Pain & $\begin{array}{l}\text { Potent neurotoxin, used in } \\
\text { treatment of dystonia, muscle } \\
\text { hyperactivity and glandular } \\
\text { hyperactivity. BTX-A may have } \\
\text { analgesic properties. }\end{array}$ & T2DM & $\begin{array}{l}\text { Intradermal injection of BTX-A } \\
\text { significantly improved painful } \\
\text { DPN }\end{array}$ & 7 \\
\hline $\begin{array}{l}\text { Monochromatic } \\
\text { Infrared Energy } \\
\text { (MIRE) }\end{array}$ & Disease & Increases blood circulation & T2DM & No improvement & 8 \\
\hline L-arginine & Disease & $\begin{array}{l}\text { Substrate for nitric oxide synthesis } \\
\text { to improve microcirculation }\end{array}$ & T2DM & No effect DPN & 9 \\
\hline Benfotiamine & Disease & $\begin{array}{l}\text { Modulates advanced glycation end } \\
\text { products. }\end{array}$ & T1DM & $\begin{array}{l}\text { No effect on peripheral nerve } \\
\text { function }\end{array}$ & 11 \\
\hline
\end{tabular}

diabetes carried features similar to patients with diabetes, particularly in regards to obesity and MetS. Since then, seven international population-based studies-five cross-sectional and two-longitudinalspanning the United States, Europe, and China have shown obesity to be the second most significant metabolic risk factor for neuropathy after diabetes. ${ }^{35-40}$ Waist circumference and diabetes are the most significant risk factors for neuropathy, ${ }^{36}$ with waist circumference associating with the greatest number of neuropathy outcome measures. ${ }^{37}$ In addition, the likelihood of symptomatic CSPN rises as the number of MetS features increases. Furthermore, in patients with established DPN, obesity and hyperlipidemia accelerate the rate of DPN development. ${ }^{41}$

Obesity is the main driver of MetS, producing a chronic state of low-grade metabolic inflammation and an elevated level of long-chain fatty acids that places undue burden on the peripheral nervous system. ${ }^{35}$ In line with such findings, CSPN in the setting of obesity and MetS is now classified as obesity- or MetS-associated neuropathy. Dyslipidemia, a component of the MetS criteria, warrants particular attention. Hypertriglyceridemia independently associates with the development of $\mathrm{CSPN}^{42}$ decreased sural nerve myelinated fiber density, ${ }^{43}$ loss of intraepidermal nerve fiber density (IENFD), ${ }^{41}$ the progression of established DPN, ${ }^{43}$ and the likelihood of lower limb amputations. ${ }^{44}$ Conversely, lipid lowering therapy reduces the likelihood of the long-term development of DPN, ${ }^{45,46}$ as well as the risk of lower limb amputation. ${ }^{47}$

In addition, impaired fasting glucose (IFG) and impaired glucose tolerance (IGT), which form part of the MetS diagnostic criteria, independently associate with the development of CSPN, and warrant discussion. Cross-sectional data from the MONICA/KORA study showed a neuropathy prevalence of $8.7 \%$ and $4.2 \%$ in patients with IGT and IFG, respectively. ${ }^{48}$ The PROMISE longitudinal study showed that prediabetic patients (IGT or IFG) carried the same prevalence of neuropathy at 3-year follow-up (50\%) as diabetics. ${ }^{49}$ In addition, when looking at patients with established CSPN, the prevalence of IFG can be as high as $56 \% .^{50}$

Somatic small unmyelinated $C$ fibers, quantified through IENFD, are particularly sensitive at capturing early DPN. Equally important is the capacity of these somatic small fibers to regenerate, and thus to serve as primary outcome measures for clinical trials. ${ }^{51}$ Also, corneal confocal microscopy is a rapid, validated, non-invasive and in vivo measure of small fiber function in diabetic neuropathy, ${ }^{52}$ which has comparable accuracy to IENFD. ${ }^{53}$ Corneal confocal microscopy also correlates with functional measures of neuropathy severity ${ }^{54}$ and tracks improvement in diabetic patients after simultaneous pancreaskidney transplant. ${ }^{55}$ Thermal perception threshold (TT) testing is a third validated and sensitive modality that captures diabetic small fiber neuropathy quite well, ${ }^{56}$ and can also be used to distinguish healthy patients from those with small fiber neuropathy. ${ }^{57}$ However, lack of consensus on stimulus application, location, and sensations tested hinders it more widespread adoption. ${ }^{58}$

\section{3 | DYSLIPIDEMIA, BIOENERGETICS, AND INFLAMMATION}

\section{1 | Murine models}

In light of the clear clinical association between MetS and CSPN, murine models were developed with the aim of understanding pathomechanisms and developing concordant therapeutic interventions for patients with DPN. In vitro, in vivo, and clinical studies focused on mechanisms underlying the pathogenic role of 
hyperlipidemia and hyperglycemia on neuropathy. Juvenile genetic murine models of prediabetes and T2DM arose, illustrating that hyperglycemia was not the only driver of peripheral neuropathy. ${ }^{59,60}$ Murine models of T2DM, including leptin (ob/ob) and leptin receptor $(d b / d b)$ knockout models, are used to identify molecular pathways that underlie neuropathy pathogenesis and are conserved between murine models and humans. ${ }^{61}$ In addition, C57BL/6J diet-induced murine models now exist, in which a lard-based, high-fat diet (HFD) chow, consisting of elevated levels of long-chain fatty acids, induces prediabetes and neuropathy. ${ }^{62,63}$ The HFD-fed C57BL/6J mice exposed to low-dose streptozotocin serve as models for T2DM. ${ }^{64}$ All of these murine models display neuropathic features, with increased thermal latency, reduced nerve conduction velocity, and IENFD loss.

\section{2 | Mitochondria and bioenergetics}

Numerous studies explored the effect of T2DM and MetS, particularly dyslipidemia, on the mitochondrion and bioenergetics in sensory neurons and the peripheral nerves (Figure 1). Disorders of fission, fusion, oxidative phosphorylation, and mitochondrial trafficking, among others, are altered in diabetes, prediabetes, and dyslipidemia. ${ }^{65}$ Dyslipidemia mediates changes in complex lipid synthesis, which then alters mitochondrial size, morphology, and motility. ${ }^{66}$ Palmitate and stearate, for example, increase mitochondrial circularity and size, probably due to mitochondrial dysfunction, swelling, and loss of inner mitochondrial membrane structure. ${ }^{66}$ Although hyperglycemia has no effect on mitochondrial trafficking in sensory neurons, increased concentrations of long-chain fatty acids impair mitochondrial trafficking and alter mitochondrial bioenergetics experimentally. ${ }^{67}$ Palmitate, a long-chain saturated fatty acid (SFA), lowers the number and velocity of motile mitochondria and depolarizes mitochondria. ${ }^{68}$ Palmitate also induces an increased rate of ATP turnover and basal respiration. Not unlike sensory neurons, Schwann cells also show pathogenic changes in response to dyslipidemia. Schwann cells increase the expression of medium to long-chain acylcarnitines in response to long-chain fatty acid overexposure, which in turn, induces peripheral nerve injury. ${ }^{69}$ In parallel, sciatic nerves from HFD and HFD-STZ mice contain elevated levels of palmitate and stearate in complex lipids such as triglycerides and phospholipids. ${ }^{70}$ Transcriptomic and lipidomic analyses on those samples showed abnormal nerve-lipid signaling, with samples showing increased expression of diacylglycerol acyltransferase 2 (DGAT2), the enzyme involved in the last step of triglyceride synthesis. This finding was corroborated with sural nerves from dyslipidemic DPN patients. ${ }^{70}$ Of note, mitochondrial alterations also appear in intraepidermal nerve fiber samples from human subjects with DPN. ${ }^{71}$ Mitochondria slarger volumes at both distal thigh and distal leg sites in DPN patients relative to healthy controls, and also show a length dependent gradient, with distal leg nerves showing larger mitochondrial volume than distal thigh nerves. An earlier study also showed mitochondrial derangements in skin sections from 32 patients with small fiber neuropathy, in which mitochondrial respiratory chain complex IV (OXPHOS)

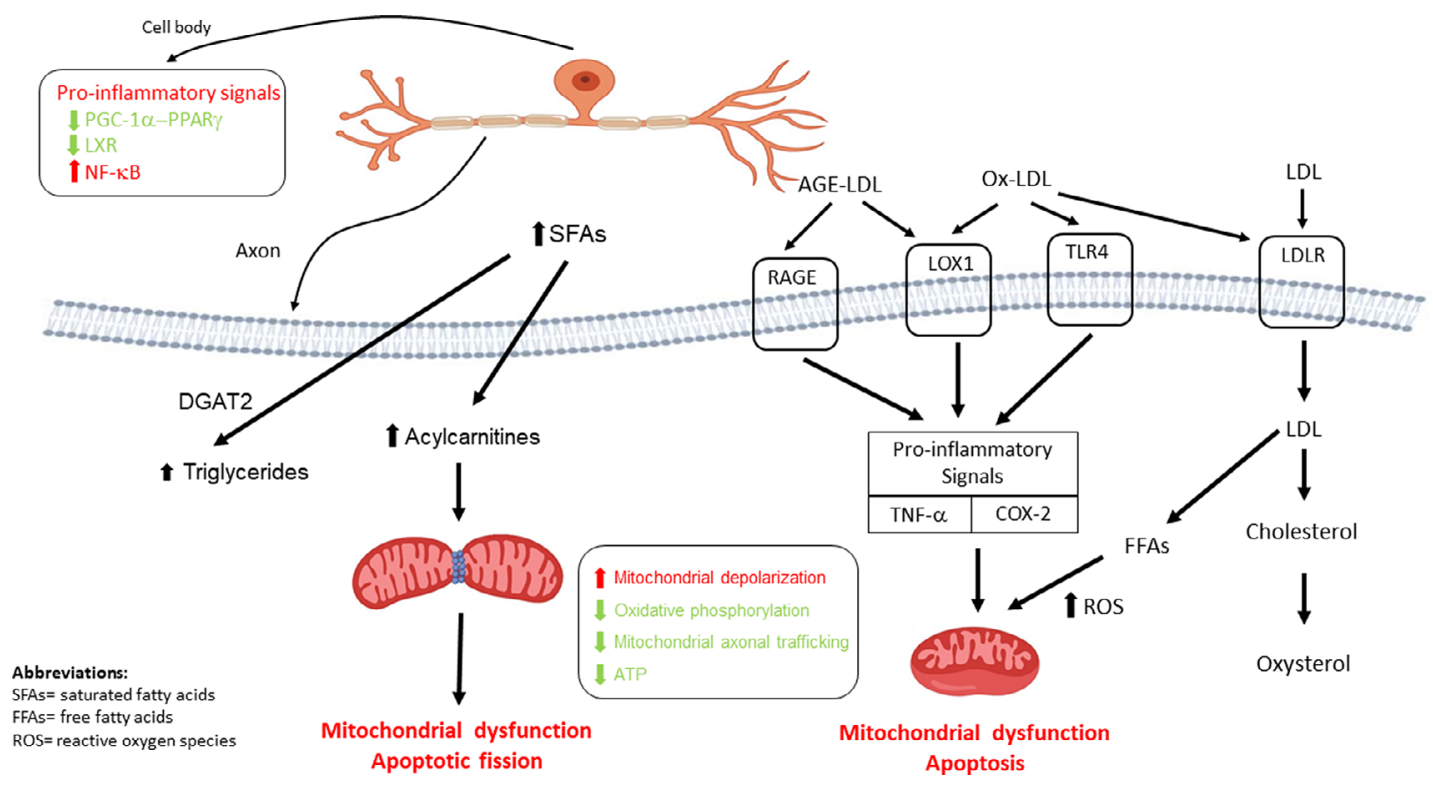

FIGURE 1 Pathogenic mitochondrial and inflammatory pathways associated with T2DM and dyslipidemia. SFAs associated with dyslipidemia and T2DM drive acylcarnitine and triglyceride formation in sensory neurons and peripheral nerves. Excess levels of acylcarnitine lead to increased mitochondrial dysfunction and apoptotic fission that may underlie T2DM DPN development. Dyslipidemia also causes an elevation in oxidized LDL (ox-LDL) and advanced glycation end-product LDL (AGE-LDL) that trigger pro-inflammatory signals including TNF- $\alpha$, IL-6, and COX-2, perturbing mitochondrial function. Similarly, LDL is metabolized intracellularly into FFAs that increase ROS and initiate mitochondrial dysfunction and apoptosis. In addition, nuclear transcription factors regulate pro-inflammatory signals (NF-kB pathway) and FFA $\beta$-oxidation (PGC-1 $\alpha$, PPAR $\gamma$, and LXR). Modulation of transcriptional regulation, fatty acid composition, or inflammatory pathways may offer therapeutic targets for the treatment of T2DM DPN. DPN, diabetic peripheral neuropathy; FFA, free fatty acid; SFAs, saturated fatty acids 
fluorescence was reduced, despite preserved intraepidermal nerve fibers. ${ }^{72}$ In addition, the normal co-localization of OXPHOS within intraepidermal and subpapillary dermal axons was also lost.

\section{3 | Substrate transport and uptake}

Transport and substrate uptake is also dysregulated in the setting of substrate overload. Free fatty acids (FFAs) are normally $\beta$-oxidized to generate $\mathrm{NADH}$ and $\mathrm{FADH}_{2}$ in Schwann cells, dorsal root ganglion sensory neurons, and axons. Of note, $\beta$-oxidation in Schwann cells requires the transport of long-chain FFAs across cell membranes. Subsequent to their uptake, FFAs are $\beta$-oxidized to produce acetyl-CoA, which is then shuttled to the tricarboxylic acid cycle for the generation of $\mathrm{NADH}$ and $\mathrm{FADH}_{2}$. In T2DM, a dyslipidemic state creates FFA substrate overload, which saturates the Schwann cell transport system and causes an accumulation of acylcarnitines. ${ }^{69}$ Schwann cells transfer accumulating acylcarnitines to sensory neurons causing axonal degeneration and mitochondrial dysfunction.

Peroxisome proliferator-activated receptors (PPARs) are also highly dysregulated in T2DM. PPARs are a superfamily of ligandactivated transcription factors of nuclear hormone receptors that perform multiple physiological functions. The PPAR- $\gamma$ subclass causes enhanced glucose metabolism and insulin sensitization. Furthermore, the PPAR- $\gamma$ coactivator- $1 \alpha$ (PGC- $1 \alpha)$ is a transcriptional co-activator and a master regulator for mitochondrial biogenesis in many tissues, including peripheral nerve, and regulates expression of proteins responsible for fatty acid uptake, particularly the fatty acid translocase CD36. ${ }^{73-75}$ Also, liver $X$ receptor (LXR) activation in murine neuropathy models is central to the reduction of endoplasmic reticulum stress and restoration of myelin lipid composition. ${ }^{76,77}$ LXRs are ligandactivated nuclear transcription factors highly linked to PPARs.

\subsection{Dyslipidemia and inflammation}

The interplay of dyslipidemia and inflammation serves as another focus of research interest in our laboratory and that of others. In the setting of substrate overload, oxidative phosphorylation fails, ATP production declines, reactive oxygen species (ROS) arise, and low density lipoproteins are oxidized, triggering mitochondrial dysfunction ${ }^{78,79}$ (Figure 1). Long-chain fatty acids penetrate the blood-nerve barrier, trigger neurogenic inflammation, and attract innate and adaptive cells, a finding corroborated with increased expression of TNF- $\alpha$ and IL-6 in DPN animal models. ${ }^{80}$ Neuronal oxidative stress triggers a cascade of downstream cytokine and chemokine production of pro-inflammatory agents, while also producing a feed-forward loop of injury. ${ }^{81}$ The generation of oxidized cholesterol (oxysterol) induces tissue injury ${ }^{82}$ by binding to the following 3 receptors: oxidized LDL receptor 1 (LOX1), a type II membrane protein located in endothelial cells ${ }^{63}$; toll-like receptor 4 (TLR4), a pattern-recognition receptor that initiates inflammatory and immune responses ${ }^{83}$; and the receptor for advanced glycation end products (RAGE), a receptor expressed in endothelial and Schwann cells which contributes to vascular injury in DPN. ${ }^{84}$ In the $d b / d b$ mouse model, multiple immune molecules are upregulated in both the early and later stages of disease. ${ }^{85}$ Inflammatory dysregulation occurs as early as 5 weeks of age in $o b / o b$ and $d b / d b$ mouse models. ${ }^{59,60,86}$ In addition, toll-like receptor signaling influences the early development of DPN in sensory neurons. ${ }^{87}$ Several inflammatory markers increase in T2DM, including interleukin-6, sialic acid, plasminogen activator inhibitor-1, fibrinogen, and C-reactive protein. ${ }^{88}$

Despite the complexity of the inflammatory process, NF-kB pathway activation is a shared pathway. NF- $\mathrm{KB}$ functions as a redoxsensitive transcription factor that is activated by hyperglycemia, oxidative stress, and pro-inflammatory cytokines. ${ }^{88}$ It modulates multiple downstream inflammatory genes, notably cyclooxygenase-2 (COX-2). Of the acute phase cytokines modulated by the NF-kB pathway, tumor necrosis factor $\alpha$ (TNF- $\alpha$ ) warrants particular attention, as it induces COX-2 overexpression, which, in turn, induces inflammatory changes that lead to DPN. ${ }^{89}$ Furthermore, the heat shock chaperone proteins (HSP) 70 and 90, responsible for protein refolding and regulating proteostasis, as well as cellular protection from oxidative stress, inflammation, and apoptosis, are a potential mechanistic target in DPN. HSPs upregulate the NF- $\kappa B$ pathway, TNF- $\alpha$, and IL- 6 by binding with high affinity to the plasma membrane. ${ }^{90}$ These chaperones can also improve neural mitochondrial bioenergetics and improve oxidant capacity. ${ }^{91}$

\section{5 | Dyslipidemic and inflammatory therapeutic targets}

In light of the above work on DPN pathomechanisms in murine models, investigators explored potential therapeutic targets through dietary reversal, unsaturated fatty acid dietary intervention, and antiinflammatory modulation (Figure 2). Dietary reversal in HFD mice is a natural focus. HFD mice switched to a standard chow diet for 4 weeks demonstrate normalization of neuropathy, as well as improved insulin sensitivity, increased weight loss, and restoration of LDL and oxidative LDL levels. ${ }^{62}$ In a separate study evaluating the sciatic nerves of HFD and HFD-STZ mice, dietary reversal from a HFD to a standard chow for 8 weeks lowers levels of pathogenic palmitate and stearate in sciatic nerves. ${ }^{70}$ The introduction of mono- and polyunsaturated fatty acids also prevents peripheral neuropathy and restores IENFD in mice fed a HFD rich in long-chain SFAs. ${ }^{66} \mathrm{~A}$ mixture of oleate, a monounsaturated fatty acid (MUFA), and palmitate at a 2:1 $\mathrm{M}$ ratio prevents palmitate-induced impairment of mitochondrial transport. ${ }^{66,68}$ Increasing the ratio of $n-3$ to $n-6$ polyunsaturated fatty acids also decreases diabetic complications in T2DM adults. ${ }^{92-94}$ Oleate prevents mitochondrial depolarization, preserves intracellular ATP levels, and reduces caspase activation by promoting lipid droplet (LD) formation, and thus prevents palmitate-induced apoptosis. ${ }^{65,95}$ In response to menhaden (fish) oil (rich in $n-3$ polyunsaturated fats), HFD-STZ mice normalize motor and sensory nerve conduction velocities as well as thermal responsiveness. ${ }^{96}$ Combinatorial therapies also provide promising therapeutic options. A diet rich in omega-3 


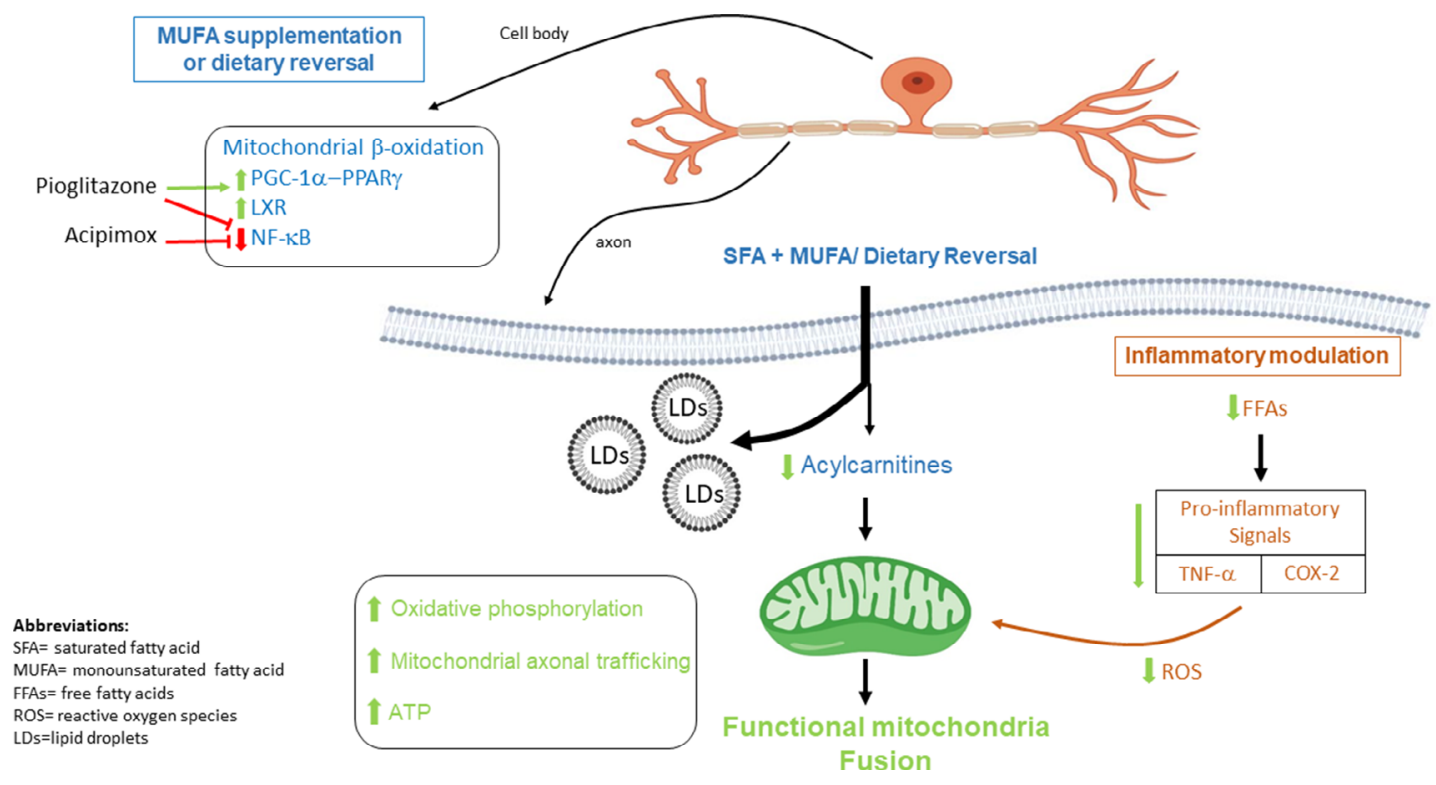

FIGURE 2 Therapeutic targets identified by dietary intervention and inflammatory pathway studies. Molecular targets were identified in preclinical studies using murine models of dyslipidemia and DPN. Dietary intervention with MUFA supplementation reverses DPN progression potentially through the sequestration of SFAs into LDs in sensory neurons. Dietary reversal from a high-fat diet to a standard diet reduces the level of SFAs in sensory neurons. Subsequent to both dietary intervention paradigms, reduced levels of acylcarnitine improves mitochondrial function and prevent apoptosis. Similarly, stimulation of PGC- $1 \alpha$, PPAR $\gamma$, and LXR transcription factors by pioglitazone activates FFA $\beta$-oxidation, improving mitochondrial function and nerve function. Pioglitazone and Acipimox both inhibit NF-kB activation of pro-inflammatory pathways. The reduction in pro-inflammatory TNF- $\alpha$, IL-6, COX-2, and ROS production prevents downstream mitochondrial dysfunction and sensory neuron apoptosis. DPN, diabetic peripheral neuropathy; FFA, free fatty acid; ROS, reactive oxygen species; SFA, saturated fatty acid

polyunsaturated fats alone or in combination with $\alpha$-lipoic acid and/or enalapril improves DPN in HFD-STZ mice as compared to untreated animals. ${ }^{97}$ Additionally, pioglitazone, an agonist of PPAR- $\gamma$ that reduces plasma levels of FFAs, improves DPN in the T2DM $d b / d b$ mouse. $^{98}$

As for inflammatory therapeutic avenues, the NF-кB pathway has emerged as a natural target. Polyunsaturated fatty acids inhibit NF- $\mathrm{KB}$ activation and nuclear translocation. ${ }^{99,100}$ In the previously cited study that showed inflammatory dysregulation as early as 5 weeks in $o b / o b$ and $d b / d b$ mice, pioglitazone and acipimox, both lipid lowering agents, improved peripheral nerve metrics. ${ }^{59}$ COX-2 selective inhibition or gene inactivation prevents large and small nerve fiber dysfunction in murine models. ${ }^{89}$ Interleukin-6 (IL-6) improves motor and sensory nerve conduction velocities ${ }^{101102}$ and corrects thermal nociception and tactile allodynia, while increasing nerve blood flow ${ }^{103,104} \cdot{ }^{105}$ Finally, with regards to heat shock chaperone proteins, modulation of Hsp70 and Hsp90 with small molecules improves DPN in T1DM animal models. ${ }^{91,106}$

\section{4 | CURRENT STATE OF HUMAN CLINICAL TRIALS AND THE ROAD AHEAD}

In light of our evolved understanding of DPN pathomechanisms and the promise of new therapeutic targets, human clinical trials have emerged to address the potential role of dietary restriction, exercise, reduction in sedentary lifestyle, and bariatric surgery in the reversal and prevention of DPN. In addition, we highlight two ongoing drug trials, although disease-modifying drug therapeutics remains in its infancy.

The Look Ahead trial showed that intensive lifestyle intervention resulted in improvement of self-reported metrics of DPN, as measured per the Michigan Neuropathy Severity Index, and per light touch sensation on physical exam. ${ }^{107}$ Three non-randomized trials have demonstrated the efficacy of exercise as a disease modifying intervention for patients with MetS, using IENFD as the primary outcome measure. The first showed improvement in 32 patients with impaired glucose tolerance as measured at 12 months. ${ }^{108}$ The second showed improvement in the regenerative capacity of small fibers in 36 patients with diabetes or MetS at 4 months after start of intervention. ${ }^{109}$ The third showed improvement in 17 DPN patients at 10 weeks after intervention. ${ }^{110}$ It is worth noting that such improvements occurred even in the absence of significant weight loss. One randomized trial for patients with T1DM and T2DM DPN demonstrated improved nerve conduction study parameters and vibration perception thresholds after a 4-year aerobic exercise regimen, although the trial did not separate T1DM from T2DM patients nor did it designate IENFD, the current gold standard, as the primary outcome measure. ${ }^{111}$ The ongoing ADAPT trial evaluates the effect of supervised exercise, individualized dietary counseling, and reduced sedentary behavior, as tracked by actigraphy, on the rate of progression of DPN. ${ }^{112}$

Bariatric surgery is also a potential intervention for DPN. An ongoing randomized trial is evaluating the effect of bariatric surgery and high intensive interval training, either in combination or alone, on 
DPN (NCT03617185). A previous prospective 6-month cohort study assessing the impact of Roux-en-Y gastric bypass on the development of DPN in T2DM patients showed an improvement in neuropathy scores. ${ }^{113}$ As for drug therapies, the Topiramate as a Disease Altering Therapy for Cryptogenic Neuropathy (TopCSPN) study is a multi-center, placebo-controlled, randomized trial in the United States that just completed enrollment, which aims to determine if topiramate can alter the natural history of MetS neuropathy (NCT02878798). Both trials employ IENFD as the primary outcome measure.

It is unknown whether single-target or multi-target interventions are needed to attain full disease-modifying efficacy. Pathway cross-talk perturbation modeling has been employed to identify connectivity changes induced by DPN and potential therapeutic interventions, and offers a novel approach to DPN disease modification strategy. ${ }^{114}$

\section{5 | CONCLUSION}

In this review, we explored modern concepts in our understanding of DPN, and how this can guide a more informed and precise approach to disease modifying therapy in the future. Despite the ubiquity of DPN and its economic cost, no approved disease modifying therapies exist, although exercise, dietary restriction, and bariatric surgery show some early favorable findings. Central to this understanding is a realization that T1DM and T2DM pathomechanisms are intrinsically different, with the type 2 DPN paradigm being much more responsive to interventions aimed at MetS rather than hyperglycemia. Through a greater appreciation of DPN pathomechanisms, particularly as it pertains to T2DM and MetS, the potential for disease modifying therapies remains promising.

\section{ACKNOWLEDGEMENTS}

E.L.F. acknowledges support from the NIH (R24DK082841, R01D107956, and R21NS102924), NovoNordisk Foundation (NNF14OC0011633), the Neuronetwork for Emerging Therapies at Michigan Medicine, and the A. Alfred Taubman Biomedical Research Institute. A.M.S. is supported by NeuroNEXT Network \& National Institute of Neurological Disorders and Stroke (NINDS). A.E.R. is supported by the National Institutes of Diabetic and Digestive and Kidney Disease (K99DK119366). B.K. is supported by the Neuronetwork for Emerging Therapies at Michigan Medicine.

\section{CONFLICT OF INTEREST}

The authors declare no potential conflict of interest.

\section{ORCID}

Bhumsoo Kim (D) https://orcid.org/0000-0002-2645-1673

\section{REFERENCES}

1. Feldman EL, Callaghan BC, Pop-Busui R, et al. Diabetic neuropathy. Nat Rev Dis Primers. 2019;5:41.
2. Callaghan BC, Little AA, Feldman EL, Hughes RA. Enhanced glucose control for preventing and treating diabetic neuropathy. Cochrane Database Syst Rev. 2012;CD007543.

3. Savelieff MG, Callaghan BC, Feldman EL. The emerging role of dyslipidemia in diabetic microvascular complications. Curr Opin Endocrinol Diabetes Obes. 2020;27:115-123.

4. Callaghan BC, Hur J, Feldman EL. Diabetic neuropathy: one disease or two? Curr Opin Neurol. 2012;25:536-541.

5. Eid S, Sas KM, Abcouwer SF, et al. New insights into the mechanisms of diabetic complications: role of lipids and lipid metabolism. Diabetologia. 2019;62:1539-1549.

6. Chen WT, Yuan RY, Chiang SC, et al. OnabotulinumtoxinA improves tactile and mechanical pain perception in painful diabetic polyneuropathy. Clin J Pain. 2013;29:305-310.

7. Ghasemi M, Ansari M, Basiri K, Shaigannejad V. The effects of intradermal botulinum toxin type a injections on pain symptoms of patients with diabetic neuropathy. J Res Med Sci. 2014;19:106-111.

8. Nawfar SA, Yacob NB. Effects of monochromatic infrared energy therapy on diabetic feet with peripheral sensory neuropathy: a randomised controlled trial. Singapore Med J. 2011;52:669-672.

9. Jude EB, Dang C, Boulton AJ. Effect of L-arginine on the microcirculation in the neuropathic diabetic foot in type 2 diabetes mellitus: a double-blind, placebo-controlled study. Diabet Med. 2010;27: 113-116.

10. Syngle A, Verma I, Krishan P, Garg N, Syngle V. Minocycline improves peripheral and autonomic neuropathy in type 2 diabetes: MIND study. Neurol Sci. 2014;35:1067-1073.

11. Fraser DA, Diep LM, Hovden IA, et al. The effects of long-term oral benfotiamine supplementation on peripheral nerve function and inflammatory markers in patients with type 1 diabetes: a 24-month, double-blind, randomized, placebo-controlled trial. Diabetes Care. 2012;35:1095-1097.

12. Ziegler D, Ametov A, Barinov A, et al. Oral treatment with alphalipoic acid improves symptomatic diabetic polyneuropathy: the SYDNEY 2 trial. Diabetes Care. 2006;29:2365-2370.

13. Ametov AS, Barinov A, Dyck PJ, et al. The sensory symptoms of diabetic polyneuropathy are improved with alpha-lipoic acid: the SYDNEY trial. Diabetes Care. 2003;26:770-776.

14. Ziegler D, Hanefeld M, Ruhnau KJ, et al. Treatment of symptomatic diabetic polyneuropathy with the antioxidant alpha-lipoic acid: a 7-month multicenter randomized controlled trial (ALADIN III Study). ALADIN III Study group. Alpha-Lipoic acid in diabetic neuropathy. Diabetes Care. 1999;22:1296-1301.

15. Ziegler D, Hanefeld M, Ruhnau KJ, et al. Treatment of symptomatic diabetic peripheral neuropathy with the anti-oxidant alpha-lipoic acid. A 3-week multicentre randomized controlled trial (ALADIN Study). Diabetologia. 1995;38:1425-1433.

16. Ruhnau KJ, Meissner HP, Finn JR, et al. Effects of 3-week oral treatment with the antioxidant thioctic acid (alpha-lipoic acid) in symptomatic diabetic polyneuropathy. Diabet Med. 1999;16:1040-1043.

17. Volchegorskii, I. A., Alekseev, M. N., Volchegorskaia, M. I. \& Rassokhina, L. M. Effect of alpha-lipoic acid and mexidol on neuroand the affective status in patients at early stages of diabetic foot syndrome. Klin Med (Mosk) 2008;86:52-59.

18. Laczy B, Cseh J, Mohás M, et al. Effects of pentoxifylline and pentosan polysulphate combination therapy on diabetic neuropathy in type 2 diabetes mellitus. Acta Diabetol. 2009;46:105-111.

19. Ansquer JC, Foucher C, Aubonnet P, Le Malicot K. Fibrates and microvascular complications in diabetes-insight from the FIELD study. Curr Pharm Des. 2009;15:537-552.

20. Bril V, Hirose T, Tomioka S, Buchanan R, Ranirestat Study G. Ranirestat for the management of diabetic sensorimotor polyneuropathy. Diabetes Care. 2009;32:1256-1260.

21. Florkowski CM, Rowe BR, Nightingale S, Harvey TC, Barnett AH. Clinical and neurophysiological studies of aldose reductase inhibitor 
ponalrestat in chronic symptomatic diabetic peripheral neuropathy. Diabetes. 1991;40:129-133.

22. Hotta N, Akanuma Y, Kawamori R, et al. Long-term clinical effects of epalrestat, an aldose reductase inhibitor, on diabetic peripheral neuropathy: the 3-year, multicenter, comparative aldose Reductase inhibitor-diabetes complications trial. Diabetes Care. 2006;29:15381544.

23. Ramirez MA, Borja NL. Epalrestat: an aldose reductase inhibitor for the treatment of diabetic neuropathy. Pharmacotherapy. 2008;28: 646-655.

24. Apfel SC. Nerve growth factor for the treatment of diabetic neuropathy: what went wrong, what went right, and what does the future hold? Int Rev Neurobiol. 2002;50:393-413.

25. Apfel SC, Kessler JA, Adornato BT, Litchy WJ, Sanders C, Rask CA. Recombinant human nerve growth factor in the treatment of diabetic polyneuropathy. NGF Study Group. Neurology. 1998;51: 695-702.

26. Valk GD, Kappelle AC, Tjon-A-Tsien AML, et al. Treatment of diabetic polyneuropathy with the neurotrophic peptide ORG 2766 . J Neurol. 1996;243:257-263.

27. Ermis N, Gullu H, Caliskan M, Unsal A, Kulaksizoglu M, Muderrisoglu H. Gabapentin therapy improves heart rate variability in diabetic patients with peripheral neuropathy. J Diabetes Complications. 2010;24:229-233.

28. Danis RP, Sheetz MJ. Ruboxistaurin: PKC-beta inhibition for complications of diabetes. Expert Opin Pharmacother. 2009;10:2913-2925.

29. Ekberg K, Johansson BL. Effect of C-peptide on diabetic neuropathy in patients with type 1 diabetes. Exp Diabetes Res. 2008;2008: 457912.

30. Evans JD, Jacobs TF, Evans EW. Role of acetyl-L-carnitine in the treatment of diabetic peripheral neuropathy. Ann Pharmacother. 2008:42:1686-1691

31. Ziegler D, Movsesyan L, Mankovsky B, Gurieva I, Abylaiuly Z, Strokov I. Treatment of symptomatic polyneuropathy with actovegin in type 2 diabetic patients. Diabetes Care. 2009;32:1479-1484.

32. Yuen KC, Baker NR, Rayman G. Treatment of chronic painful diabetic neuropathy with isosorbide dinitrate spray: a double-blind placebo-controlled cross-over study. Diabetes Care. 2002;25:16991703.

33. Cakici N, Fakkel TM, van Neck JW, Verhagen AP, Coert JH. Systematic review of treatments for diabetic peripheral neuropathy. Diabet Med. 2016;33:1466-1476.

34. Vincent AM, Callaghan BC, Smith AL, Feldman EL. Diabetic neuropathy: cellular mechanisms as therapeutic targets. Nat Rev Neurol. 2011;7:573-583.

35. Callaghan BC, Gao LL, Li Y, et al. Diabetes and obesity are the main metabolic drivers of peripheral neuropathy. Ann Clin Transl Neurol. 2018;5:397-405

36. Callaghan BC, Xia R, Reynolds E, et al. Association between metabolic syndrome components and polyneuropathy in an obese population. JAMA Neurol. 2016;73:1468-1476.

37. Callaghan BC, Xia R, Banerjee M, et al. Metabolic syndrome components are associated with symptomatic polyneuropathy independent of glycemic status. Diabetes Care. 2016;39:801-807.

38. Hanewinckel R, Drenthen J, Ligthart S, et al. Metabolic syndrome is related to polyneuropathy and impaired peripheral nerve function: a prospective population-based cohort study. J Neurol Neurosurg Psychiatry. 2016;87:1336-1342.

39. Lu B, Hu J, Wen J, et al. Determination of peripheral neuropathy prevalence and associated factors in Chinese subjects with diabetes and pre-diabetes-ShangHai diabetic neuRopathy epidemiology and molecular genetics Study (SH-DREAMS). PLoS One. 2013;8 e61053.

40. Schlesinger S, Herder C, Kannenberg JM, et al. General and abdominal obesity and incident distal sensorimotor polyneuropathy: insights into inflammatory biomarkers as potential mediators in the KORA F4/FF4 cohort. Diabetes Care. 2019;42:240-247.

41. Smith AG, Singleton JR. Obesity and hyperlipidemia are risk factors for early diabetic neuropathy. J Diabetes Complications. 2013;27: 436-442.

42. Hughes RA, Umapathi T, Gray IA, et al. A controlled investigation of the cause of chronic idiopathic axonal polyneuropathy. Brain. 2004; 127:1723-1730.

43. Wiggin TD, Sullivan KA, Pop-Busui R, Amato A, Sima AAF, Feldman EL. Elevated triglycerides correlate with progression of diabetic neuropathy. Diabetes. 2009;58:1634-1640.

44. Callaghan BC, Feldman E, Liu J, et al. Triglycerides and amputation risk in patients with diabetes: ten-year follow-up in the DISTANCE study. Diabetes Care. 2011;34:635-640.

45. Davis TM, Yeap BB, Davis WA, Bruce DG. Lipid-lowering therapy and peripheral sensory neuropathy in type 2 diabetes: the Fremantle diabetes Study. Diabetologia. 2008;51:562-566.

46. Kang EY, Chen TH, Garg SJ, et al. Association of statin therapy with prevention of vision-threatening diabetic retinopathy. JAMA Ophthalmol. 2019;137:363-371.

47. Rajamani K, Colman PG, Li LP, et al. Effect of fenofibrate on amputation events in people with type 2 diabetes mellitus (FIELD study): a prespecified analysis of a randomised controlled trial. Lancet. 2009; 373:1780-1788.

48. Ziegler D, Rathmann W, Dickhaus T, Meisinger C, Mielck A, KORA Study Group. Neuropathic pain in diabetes, prediabetes and normal glucose tolerance: the MONICA/KORA Augsburg surveys S2 and S3. Pain Med. 2009;10:393-400.

49. Lee CC, Perkins BA, Kayaniyil S, et al. Peripheral neuropathy and nerve dysfunction in individuals at high risk for type 2 diabetes: the PROMISE cohort. Diabetes Care. 2015;38:793-800.

50. Sumner CJ, Sheth S, Griffin JW, Cornblath DR, Polydefkis M. The spectrum of neuropathy in diabetes and impaired glucose tolerance. Neurology. 2003;60:108-111.

51. Polydefkis $M$, Hauer $P$, Sheth $S$, Sirdofsky $M$, Griffin JW, McArthur JC. The time course of epidermal nerve fibre regeneration: studies in normal controls and in people with diabetes, with and without neuropathy. Brain. 2004;127:1606-1615.

52. Alam U, Jeziorska M, Petropoulos IN, et al. Diagnostic utility of corneal confocal microscopy and intra-epidermal nerve fibre density in diabetic neuropathy. PLoS One. 2017;12:e0180175.

53. Jiang MS, Yuan Y, Gu ZX, Zhuang SL. Corneal confocal microscopy for assessment of diabetic peripheral neuropathy: a meta-analysis. Br J Ophthalmol. 2016;100:9-14.

54. Tavakoli M, Quattrini C, Abbott C, et al. Corneal confocal microscopy: a novel noninvasive test to diagnose and stratify the severity of human diabetic neuropathy. Diabetes Care. 2010;33: 1792-1797.

55. Tavakoli M, Mitu-Pretorian M, Petropoulos IN, et al. Corneal confocal microscopy detects early nerve regeneration in diabeticneuropathy after simultaneous pancreas and kidney transplantation. Diabetes. 2013;62:254-260.

56. Jimenez-Cohl P, Grekin C, Leyton C, Vargas C, Villaseca R. Thermal threshold: research study on small fiber dysfunction in distal diabetic polyneuropathy. J Diabetes Sci Technol. 2012;6:177-183.

57. Medici C, Barraza G, Castillo CD, et al. Disturbed sensory perception of changes in thermoalgesic stimuli in patients with small fiber neuropathies. Pain. 2013;154:2100-2107.

58. Bakkers M, Faber CG, Peters $\mathrm{MJH}$, et al. Temperature threshold testing: a systematic review. J Peripher Nerv Syst. 2013;18:7-18.

59. Hur J, Dauch JR, Hinder LM, et al. The metabolic syndrome and microvascular complications in a murine model of type 2 diabetes. Diabetes. 2015;64:3294-3304.

60. O'Brien PD, Hur J, Hayes JM, Backus C, Sakowski SA, Feldman EL. BTBR $\mathrm{Ob} / \mathrm{Ob}$ mice as a novel diabetic neuropathy model: 
neurological characterization and gene expression analyses. Neurobiol Dis. 2015;73:348-355.

61. McGregor BA, Eid S, Rumora AE, et al. Conserved transcriptional signatures in human and murine diabetic peripheral neuropathy. Sci Rep. 2018;8:17678.

62. Hinder LM, O'Brien PD, Hayes JM, et al. Dietary reversal of neuropathy in a murine model of prediabetes and metabolic syndrome. Dis Model Mech. 2017;10:717-725.

63. Vincent AM, Hayes JM, McLean LL, Vivekanandan-Giri A, Pennathur S, Feldman EL. Dyslipidemia-induced neuropathy in mice: the role of oxLDL/LOX-1. Diabetes. 2009:58:2376-2385.

64. O'Brien PD, Hinder LM, Rumora AE, et al. Juvenile murine models of prediabetes and type 2 diabetes develop neuropathy. Dis Model Mech. 2018;11:2-4.

65. Rumora AE, Savelieff MG, Sakowski SA, Feldman EL. Disorders of mitochondrial dynamics in peripheral neuropathy: clues from hereditary neuropathy and diabetes. Int Rev Neurobiol. 2019;145:127-176.

66. Rumora AE, LoGrasso G, Hayes JM, et al. The divergent roles of dietary saturated and monounsaturated fatty acids on nerve function in murine models of obesity. J Neurosci. 2019;39:3770-3781.

67. Rumora $A E$, Lentz $\mathrm{SI}$, Hinder LM, et al. Dyslipidemia impairs mitochondrial trafficking and function in sensory neurons. FASEB J. 2018;32:195-207.

68. Rumora AE, LoGrasso G, Haidar JA, Dolkowski JJ, Lentz SI, Feldman EL. Chain length of saturated fatty acids regulates mitochondrial trafficking and function in sensory neurons. J Lipid Res. 2019;60:58-70.

69. Viader A, Sasaki Y, Kim S, et al. Aberrant Schwann cell lipid metabolism linked to mitochondrial deficits leads to axon degeneration and neuropathy. Neuron. 2013;77:886-898.

70. O'Brien PD, Guo K, Eid SA, et al. Integrated lipidomic and transcriptomic analyses identify altered nerve triglycerides in mouse models of prediabetes and type 2 diabetes. Dis Model Mech. 2020;13: 2-5.

71. Hamid HS, Mervak CM, Münch AE, et al. Hyperglycemia- and neuropathy-induced changes in mitochondria within sensory nerves. Ann Clin Transl Neurol. 2014;1:799-812.

72. Casanova-Molla J, Morales M, Garrabou G, et al. Mitochondrial loss indicates early axonal damage in small fiber neuropathies. J Peripher Nerv Syst. 2012;17:147-157.

73. Pande M, Hur J, Hong $Y$, et al. Transcriptional profiling of diabetic neuropathy in the BKS db/db mouse: a model of type 2 diabetes. Diabetes. 2011;60:1981-1989.

74. Hur J, Sullivan KA, Pande M, et al. The identification of gene expression profiles associated with progression of human diabetic neuropathy. Brain. 2011;134:3222-3235.

75. Hardin H, Guo Z, Shan W, et al. The roles of the epithelialmesenchymal transition marker PRRX1 and miR-146b-5p in papillary thyroid carcinoma progression. Am J Pathol. 2014;184:2342-2354.

76. Cermenati G, Abbiati F, Cermenati S, et al. Diabetes-induced myelin abnormalities are associated with an altered lipid pattern: protective effects of LXR activation. J Lipid Res. 2012;53:300-310.

77. Kemp K, Griffiths J, Campbell S, Lovell K. An exploration of the follow-up up needs of patients with inflammatory bowel disease. J Crohns Colitis. 2013;7:e386-e395.

78. Chowdhury SK, Smith DR, Fernyhough P. The role of aberrant mitochondrial bioenergetics in diabetic neuropathy. Neurobiol Dis. 2013; 51:56-65.

79. Fernyhough P. Mitochondrial dysfunction in diabetic neuropathy: a series of unfortunate metabolic events. Curr Diab Rep. 2015;15:89.

80. O'Brien PD, Sakowski SA, Feldman EL. Mouse models of diabetic neuropathy. ILAR J. 2014;54:259-272.

81. Stavniichuk R, Shevalye H, Lupachyk $\mathrm{S}$, et al. Peroxynitrite and protein nitration in the pathogenesis of diabetic peripheral neuropathy. Diabetes Metab Res Rev. 2014;30:669-678.
82. Jang ER, Lee CS. 7-ketocholesterol induces apoptosis in differentiated PC12 cells via reactive oxygen species-dependent activation of NF- $\mathrm{kB}$ and Akt pathways. Neurochem Int. 2011;58:52-59.

83. Nowicki M, Müller K, Serke H, et al. Oxidized low-density lipoprotein (oxLDL)-induced cell death in dorsal root ganglion cell cultures depends not on the lectin-like oxLDL receptor-1 but on the toll-like receptor-4. J Neurosci Res. 2010;88:403-412.

84. Vincent AM, Perrone L, Sullivan KA, et al. Receptor for advanced glycation end products activation injures primary sensory neurons via oxidative stress. Endocrinology. 2007;148:548-558.

85. Hinder LM, Murdock BJ, Park M, et al. Transcriptional networks of progressive diabetic peripheral neuropathy in the $\mathrm{db} / \mathrm{db}$ mouse model of type 2 diabetes: an inflammatory story. Exp Neurol. 2018; 305:33-43.

86. Lupachyk S, Watcho P, Hasanova N, Julius U, Obrosova IG. Triglyceride, nonesterified fatty acids, and prediabetic neuropathy: role for oxidative-nitrosative stress. Free Radic Biol Med. 2012;52:12551263.

87. Elzinga S, Murdock BJ, Guo K, et al. Toll-like receptors and inflammation in metabolic neuropathy; a role in early versus late disease? Exp Neurol. 2019;320:112967.

88. Shoelson SE, Lee J, Goldfine AB. Inflammation and insulin resistance. J Clin Invest. 2006;116:1793-1801.

89. Kellogg AP, Wiggin TD, Larkin DD, Hayes JM, Stevens MJ, PopBusui R. Protective effects of cyclooxygenase-2 gene inactivation against peripheral nerve dysfunction and intraepidermal nerve fiber loss in experimental diabetes. Diabetes. 2007;56:2997-3005.

90. Asea A, Kraeft SK, Kurt-Jones EA, et al. HSP70 stimulates cytokine production through a CD14-dependant pathway, demonstrating its dual role as a chaperone and cytokine. Nat Med. 2000;6:435-442.

91. Ma J, Pan P, Anyika M, Blagg BS, Dobrowsky RT. Modulating molecular chaperones improves mitochondrial bioenergetics and decreases the inflammatory Transcriptome in diabetic sensory neurons. ACS Chem Nerosci. 2015;6:1637-1648.

92. Han E, Yun Y, Kim G, et al. Effects of Omega-3 fatty acid supplementation on diabetic nephropathy progression in patients with diabetes and hypertriglyceridemia. PLoS One. 2016;11:e0154683.

93. Lewis EJH, Perkins BA, Lovblom LE, Bazinet RP, Wolever TMS, Bril V. Effect of omega-3 supplementation on neuropathy in type 1 diabetes: A 12-month pilot trial. Neurology. 2017;88:2294-2301.

94. Sala-Vila A, Díaz-López A, Valls-Pedret C, et al. Dietary marine $\omega-3$ fatty acids and incident sight-threatening retinopathy in middle-aged and older individuals with type 2 diabetes: prospective investigation from the PREDIMED trial. JAMA Ophthalmol. 2016;134:1142-1149.

95. Kwon B, Lee HK, Querfurth HW. Oleate prevents palmitate-induced mitochondrial dysfunction, insulin resistance and inflammatory signaling in neuronal cells. Biochim Biophys Acta. 2014;1843:14021413.

96. Shevalye H, Yorek MS, Coppey LJ, et al. Effect of enriching the diet with menhaden oil or daily treatment with resolvin D1 on neuropathy in a mouse model of type 2 diabetes. J Neurophysiol. 2015;114: 199-208.

97. Yorek MS, Obrosov A, Shevalye H, Coppey LJ, Kardon RH, Yorek MA. Early vs. late intervention of high fat/low dose streptozotocin treated C57BI/6J mice with enalapril, $\alpha$-lipoic acid, menhaden oil or their combination: effect on diabetic neuropathy related endpoints. Neuropharmacology. 2017;116:122-131.

98. Hinder $L M$, Park M, Rumora $A E$, et al. Comparative RNA-Seq transcriptome analyses reveal distinct metabolic pathways in diabetic nerve and kidney disease. J Cell Mol Med. 2017;21:21402152

99. Liu JJ, Green P, John Mann J, Rapoport SI, Sublette ME. Pathways of polyunsaturated fatty acid utilization: implications for brain function in neuropsychiatric health and disease. Brain Res. 2015;1597: 220-246. 
100. Li MY, Wang YY, Cao R, et al. Dietary fish oil inhibits mechanical allodynia and thermal hyperalgesia in diabetic rats by blocking nuclear factor-кB-mediated inflammatory pathways. J Nutr Biochem. 2015;26:1147-1155.

101. Libby P, Ridker PM, Maseri A. Inflammation and atherosclerosis. Circulation. 2002;105:1135-1143.

102. Goldberg RB. Cytokine and cytokine-like inflammation markers, endothelial dysfunction, and imbalanced coagulation in development of diabetes and its complications. J Clin Endocrinol Metab. 2009;94: 3171-3182.

103. Cameron NE, Cotter MA. Pro-inflammatory mechanisms in diabetic neuropathy: focus on the nuclear factor kappa B pathway. Curr Drug Targets. 2008;9:60-67.

104. Cotter MA, Gibson TM, Nangle MR, Cameron NE. Effects of interleukin-6 treatment on neurovascular function, nerve perfusion and vascular endothelium in diabetic rats. Diabetes Obes Metab. 2010;12:689-699.

105. Andriambeloson E, Baillet C, Vitte PA, Garotta G, Dreano M, Callizot N. Interleukin-6 attenuates the development of experimental diabetes-related neuropathy. Neuropathology. 2006;26: 32-42.

106. Ma J, Farmer KL, Pan P, et al. Heat shock protein 70 is necessary to improve mitochondrial bioenergetics and reverse diabetic sensory neuropathy following KU-32 therapy. J Pharmacol Exp Ther. 2014; 348:281-292.

107. Look AHEAD Research Group. Effects of a long-term lifestyle modification programme on peripheral neuropathy in overweight or obese adults with type 2 diabetes: the look AHEAD study. Diabetologia. 2017;60:980-988.

108. Smith AG, Russell J, Feldman EL, et al. Lifestyle intervention for pre-diabetic neuropathy. Diabetes Care. 2006;29:1294 1299.
109. Singleton JR, Marcus RL, Lessard MK, Jackson JE, Smith AG. Supervised exercise improves cutaneous reinnervation capacity in metabolic syndrome patients. Ann Neurol. 2015;77:146-153.

110. Kluding PM, Pasnoor M, Singh R, et al. The effect of exercise on neuropathic symptoms, nerve function, and cutaneous innervation in people with diabetic peripheral neuropathy. J Diabetes Complications. 2012;26:424-429.

111. Balducci S, lacobellis G, Parisi L, et al. Exercise training can modify the natural history of diabetic peripheral neuropathy. J Diabetes Complications. 2006;20:216-223.

112. Kluding PM, Singleton JR, Pasnoor M, et al. Activity for diabetic polyneuropathy (ADAPT): Study design and protocol for a 2-site randomized controlled trial. Phys Ther. 2017;97:20-31.

113. Müller-Stich BP, Fischer L, Kenngott HG, et al. Gastric bypass leads to improvement of diabetic neuropathy independent of glucose normalization-results of a prospective cohort study (DiaSurg 1 study). Ann Surg. 2013;258:760-765. discussion 765-766.

114. de Anda-Jáuregui G, Guo K, McGregor BA, Feldman EL, Hur J. Pathway crosstalk perturbation network modeling for identification of connectivity changes induced by diabetic neuropathy and pioglitazone. BMC Syst Biol. 2019;13:1.

How to cite this article: Stino AM, Rumora AE, Kim B, Feldman EL. Evolving concepts on the role of dyslipidemia, bioenergetics, and inflammation in the pathogenesis and treatment of diabetic peripheral neuropathy. J Peripher Nerv Syst. 2020;25:76-84. https://doi.org/10.1111/jns.12387 